\title{
HAWAIIAN VOLCANO OBSERVATORY - AN EXPANDING RESEARCH EFFORT
}

by

John P. Lockwood

\author{
Gordon P. Eaton and Robert I. Tilling
}

\begin{abstract}
Measurement of the dynamic changes of volcanoes has been evaluated to provide a developing capability for both short-term and long-term prediction of volcanic eruption. This fundamental contribution to hazard appraisal uses not only conventional field mapping, geophysics, geochemistry and geochronology, but also the new and rapidly evolving technologies related to scientific use of submersibles and satellite imagery. The U.S. Geological Survey's Hawaiian Volcano Observatory has made a fundamental contribution to a better understanding of the origin and evolution of volcanoes. This information is now used globally to predict and mitigate eruptions which could threaten human habitation.
\end{abstract}

\section{Background}

"Ne plus haustae aut obrutae urbes" ("No more shall the cities be destroyed") - with this motto, the Hawaiian Volcano Research Association (HVRA) was founded in 1911. The enthusiastic interest of Hawaiian residents in the study of volcanoes had been kindled by a Honolulu lecture by Professor Thomas A. Jaggar in 1909, and the HVRA successfully petitioned the Massachusetts Institute of Technology to expend monies from the newly endowed Whitney Fund to establish a volcano observatory at Kilauea volcano on the Island of Hawaii. Additional funds were subscribed by philanthropists from both Honolulu and Hilo, and Jaggar was invited by the HVRA to take "leave of absence" from MIT to establish the Hawaiian Volcano Observatory (HVO). He accepted, and arrived at Kilauea on January 17, 1912, which marks the official founding of the Observatory. His "leave of absence" was to be permanent: Jaggar remained at HVO as Director for 28 years until his retirement in 1940 .

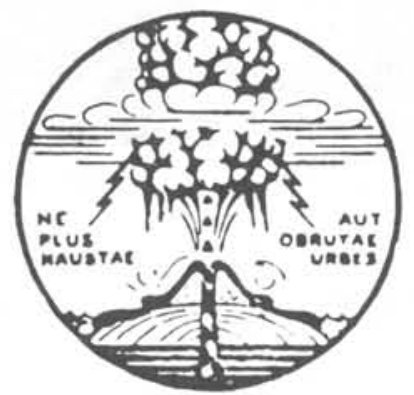

Logo of Hawaiian Volcano Research Association.

HVO's early history was a checkered affair. It was funded at various times by HVRA, the U.S. Weather Bureau, the U.S. Geological Survey, and the National Park Service. Personal funds of both Jaggar and his Hawaiian friends figured in its support as well. In 1948, HVO was transferred from the National Park Service back to the USGS, where it had first been assigned in 1924. It has remained a Geological Survey research facility ever since, supported now by the Survey's Volcano Hazards Program.

\section{HVO's Test Facilities}

When HVO was founded, very little was known about the workings of volcanoes and essentially nothing was known about the quantitative physical measurements that should or could be made. Thus, from its earliest days HVO has been a test facility where techniques and instruments to measure the dynamic changes of active volcanoes have been conceived, constructed, tested, and employed.
Owing to the ingenuity of HVO staff over the decades, many of the basic tools and techniques for volcanic observation have been developed here. HVO staff have geodetically monitored and analyzed changes on Kilauea to determine the location, configuration, and interconnection of magma storage areas. A network of more than 40 seismometers provides additional information that allows one to study changes in deformation and magma movement within the active volcanoes. The petrologic evolution of Kilauea's magma is now fairly well understood, and important physical properties of this magma have been measured in situ. Kilauea and Mauna Loa today have the most complete geodetic and geophysical monitoring networks of any volcanoes in the world. With these monitoring techniques, short-term (hours or days) prediction of eruptive activity is on its way to becoming routine.

This short-term predictive capability is generally serving well, and has allowed the staff of Hawaii Volcanoes National Park (where many eruptions occur) to successfully evacuate and close off areas of the Park where local eruptive activity is anticipated.

\section{Long-term Predictions}

With increasing frequency, however, HVO is being asked to provide long-term (years or decades) predictions of eruptive trends by investors, land developers, insurance companies, banks, and governmental agencies that need accurate evaluations of the risk to present and contemplated capital investments on the Island of Hawaii. Because longterm patterns of future eruptive activity are not amenable to evaluation by observation and analysis of contemporary activity alone, HVO is undertaking major efforts to unravel the geological evolution and prehistoric eruptive patterns of Hawaii's active volcanoes.

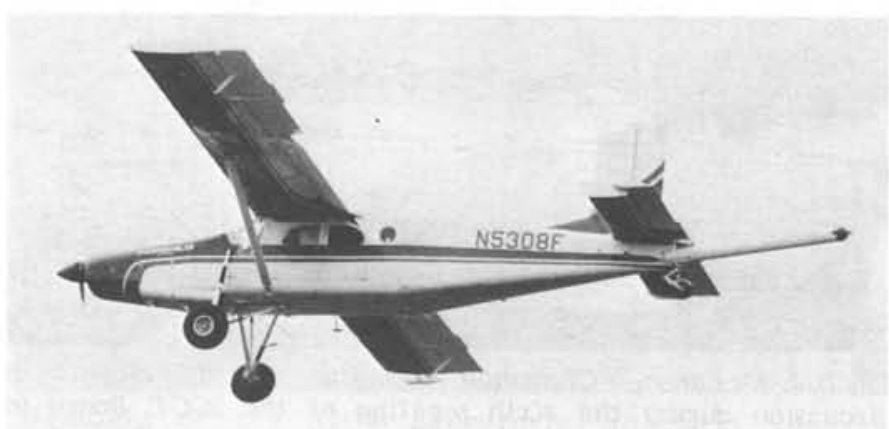

- Porter STOL aircraft recently in Hawaii to conduct geophysical surveys of active volcanoes. 


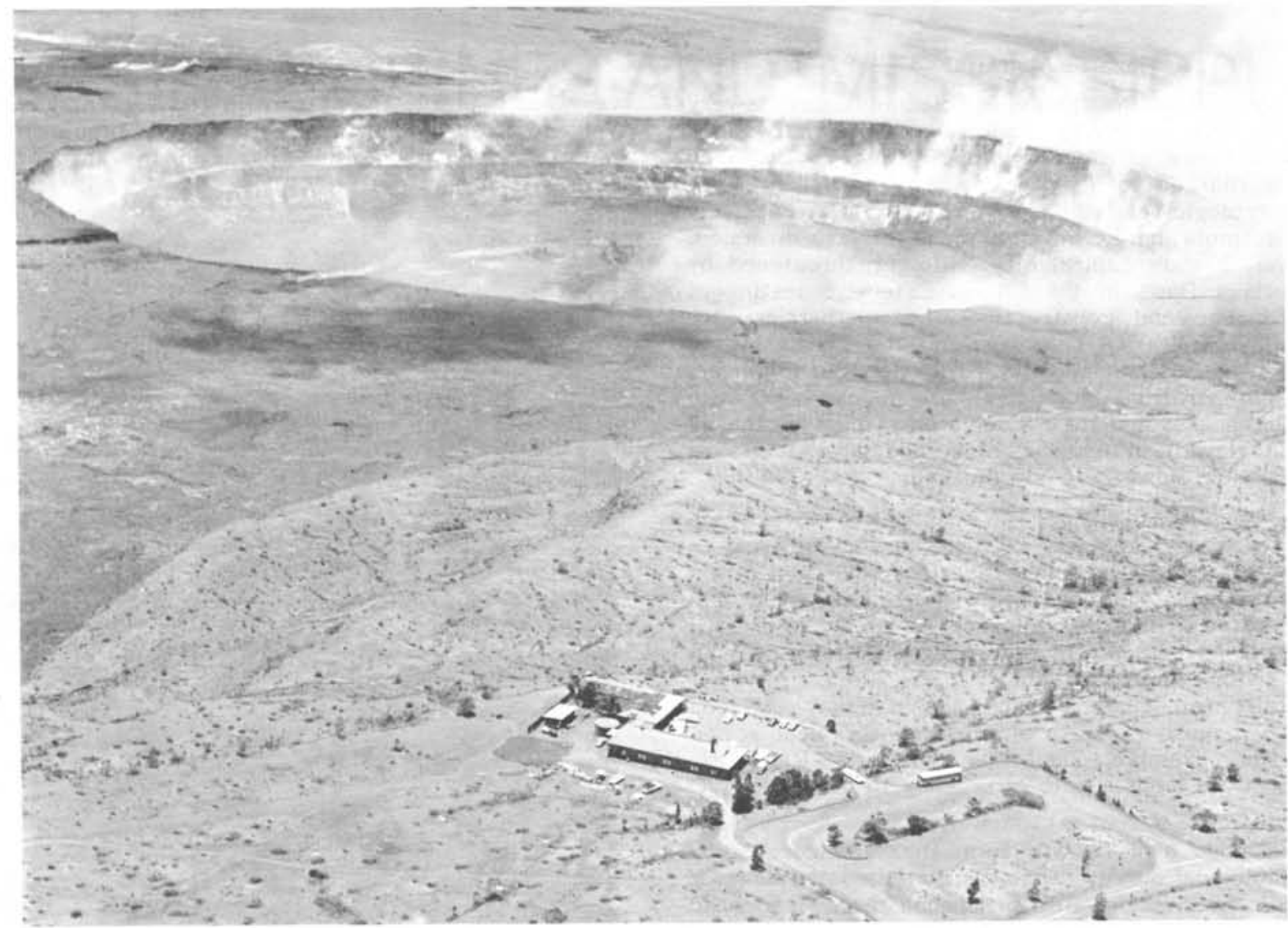

Aerial view of HVO, with Kilauea Caldera and Halemaumau Crater in background.

Eruptive activity during the brief time of written records (about 150 years) may well be atypical of long-term patterns. In an effort to extend the known geologic history of Hawaii's active volcanoes, four geologic mapping projects on Mauna Loa and Kilauea by present and former HVO staff are devoted to deciphering the complex late prehistoric record of these volcanoes. A massive geochronometric program to date prehistoric eruptions is underway, and nearly 100 samples of buried organic matter have been recently recovered from beneath prehistoric lavas of Mauna Loa and Kilauea for dating by the ${ }^{14} \mathrm{C}$ method at the USGS Radiocarbon Laboratory in Reston, Virginia. The initial age determinations have proved to be most exciting, and have shown the surface rocks of both volcanoes to be surprisingly young. However, field mapping alone will not tell enough about Hawaii's volcanoes, and HVO staff and their colleagues are also taking to the air and sea in an effort to obtain needed geophysical information.

Surface marine studies are being expanded with the cooperation of the Geological Survey's Pacific-Arctic Marine Geology Branch and the U.S. Coast Guard. Participation in a co-operative program between the Lamont-Doherty Geological Observatory and the U.S. Navy has enabled HVO staff to view submarine volcanic vents, modern submarine flows, and other fascinating volcanic features at depths as great as $2,000 \mathrm{~m}$ below sea level.

Remote sensing and other airborne geophysica! techniques are being used to evaluate volcanic structure through a study of NASA imagery and by detailed aerial thermal infrared, magnetic, and very low frequency electromagnetic surveys flown by colleagues from the Geological Survey's Branch of Petrophysics and Remote Sensing and Branch of Electromagnetics and Geomagnetism. It is also recognized that changes in volcanic gas composition and temperature may signal impending eruptive activity, and a gas geochemist has recently joined the HVO staff. Studies in electrical geophysics and the monitoring of tiny gravitational changes, begun in recent years, have proved very fruitful in understanding the subsurface movement of magma, and these programs are being expanded. A small computer being installed this year will give staff a critically needed real-time capability for locating shifting earthquake epicenters. It will complement an existing acoustic coupler that has allowed staff to communicate with the USGS computer system on the mainland. The present HVO staff is cramped in an old, outdated facility, and consideration is being given to an upgraded building to house an expanded staff.

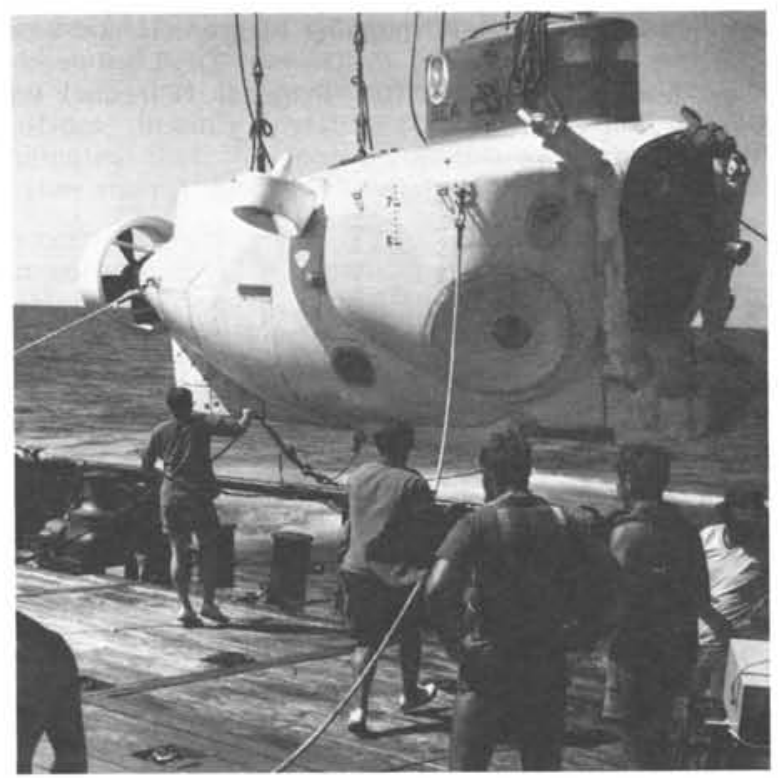

U.S. Navy Deep Submergence Vehicle No. 4-"Sea Cliff" preparing to dive on submarine volcanic vents off Hawaii with HVO observer aboard in U.S. Navy - Lamont-Doherty Geological Observatory diving program. 


\section{Hazards Appraisal}

The appraisal and mitigation of volcanic hazards is very much at the core of HVO's work today, especially since passage of the Federal Disaster Relief Act of 1974, by which the USGS is charged with a responsibility to make timely warnings of geologic-related hazards. HVO staff are actively involved in formulating contingency plans for lava diversion, should Hawaii Island's capital city, Hilo, be threatened by Mauna Loa lava flows in the future. Extensive testing of military ordnance and construction of test barriers for redirecting lava flows has been carried out recently by the U.S. Air Force, U.S. Army and U.S. Army Corps of Engineers with HVO co-operation. More than 200 people have been killed by earthquakes and their associated effects (primarily tsunamis) in Hawaii in historic time, and new studies of seismic hazards on Hawaii are now planned.

While Hawaii is an excellent place to investigate volcano-related hazards because of the frequency of eruptive activity, the results of these investigations have application far beyond Hawaii's shores. The western part of North America is dotted with active volcanoes which are at present dormant. There have been remarkably few eruptions in North America in historic time, particularly in the 20 th century, but it is generally felt that renewed activity may be long overdue. The extensive growth of urban centers near active volcanoes (for example, near the Cascade Range in northwestern U.S.) lends a note of urgency to plans for HVO expansion.

Staff trained at HVO will form the solid core of an expanded Geological Survey capability to assess the hazards of active volcanoes in Hawaii, Alaska, and the Cascades, to monitor dormant volcanoes, and to respond to renewed activity whenever and wherever it occurs. Such staff would also be available to assist foreign countries with volcano hazards problems whenever co-operative assistance is requested.
Ne plus haustae aut obrutae urbes - these words figured very much in the minds of the founders of the Hawailan Volcano Observatory. They still figure prominently in the work at HVO, and will surely be in the thoughts of HVO scientists in the future.

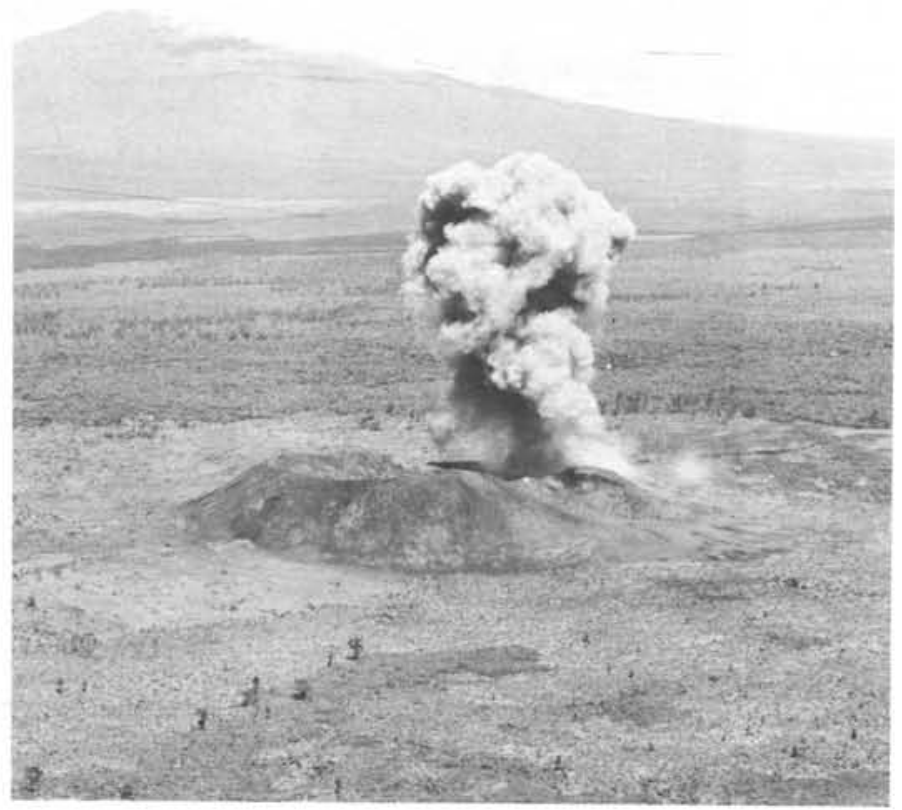

Dust cloud from blast of $900 \mathrm{~kg}$ aerial bomb in U.S. Air Force - HVO tests conducted on a military bombing range to evaluate effects of explosives on lava diversion target analogs.

\section{ABOUT THE AUTHORS:}

Geologist at the Hawaiian Volcano Observatory, John P. Lockwood received his Ph.D. from Princeton in 1965, and is investigating the volcanic hazards of Mauna Loa and the means of diverting lava flows. Prior to moving to Hawaii, he participated in the field mapping of granitic and volcanic rocks in the Sierra Nevada, California. Dr. Lockwood took part in launching the IGCP Project "Circum Pacific Plutonism".

John P. Lockwood

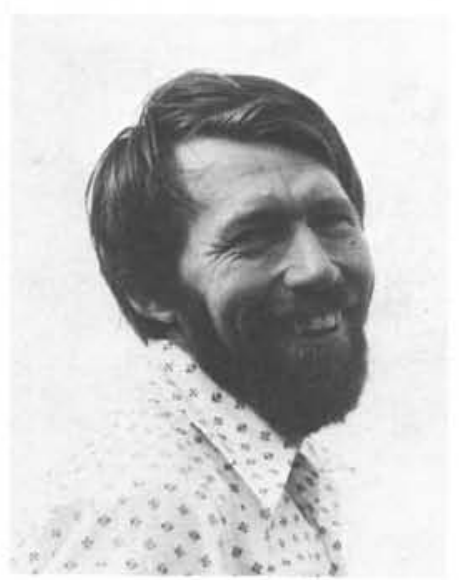

Chief of the U.S. Geological Survey, Office of Geochemistry and Geophysics, Robert I. Tilling received his Ph.D. at Yale in 1963 , is a former Scientist-in-Charge of the Hawaiian Volcano Observatory and is responsible for administering the Geological Survey's Volcano Hazards Program.

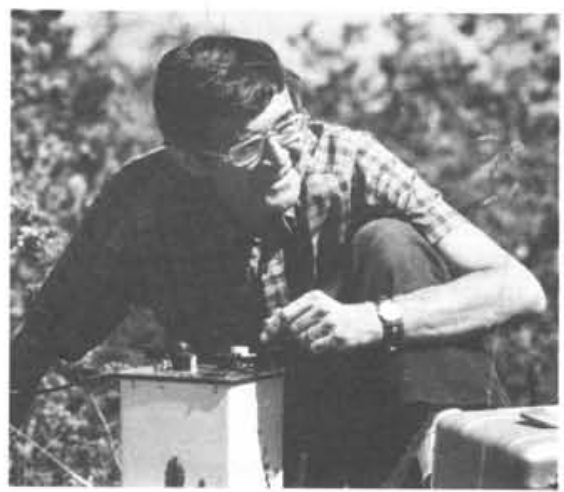

Gordon P. Eaton

Scientist-in-Charge of the Hawailan Volcano Observatory, Gordon P. Eaton received his Ph.D. in geology and geophysics at the California Institute of Technology in 1957. He is especially interested in the application of exploration geophysical techniques to the study of active volcanoes and the potential health hazards posed by volcanic gases and their contributions to the atmosphere.

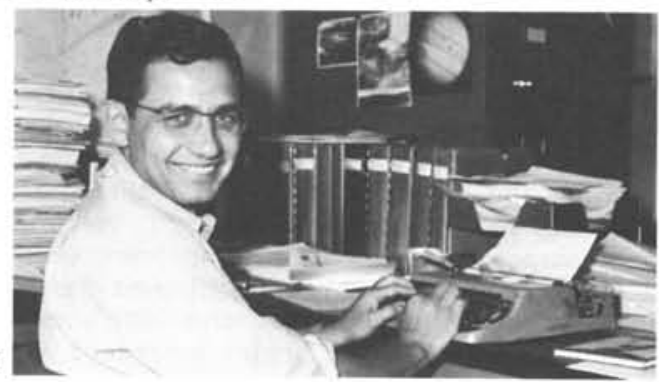

